\title{
Comparative Evaluation of Efficacy of Four Different Materials in the Repair of Amalgam Restorations: An In Vitro Study
}

\author{
Aniket Chavan ${ }^{1}$, Pawan Darak ${ }^{2}$, Saritha Vallabhaneni ${ }^{3}$, Sayed Mateen Peerzade ${ }^{4}$, Suresh Shenvi ${ }^{5}$, Thimmanagowda N Patil ${ }^{6}$
}

\begin{abstract}
Aim: This study was aimed to compare the microleakage of amalgam restorations repaired with bonded amalgam, composite resin, ormocer, and glass ionomer restorative material.

Materials and methods: Sixty extracted maxillary human premolars were prepared and restored with class I amalgam. A simulated defect was prepared that included the cavosurface margin on restorations, and the premolars were assigned to four treatment groups ( $n=15)$ : In group I, premolars were treated by bonded amalgam; in group II, premolars were repaired with composite resin; in group III, premolars were repaired by ormocer; and in group IV, premolars were repaired with glass ionomer restorative material. The teeth were immersed in $50 \%$ silver nitrate solution, thermocycled, sectioned longitudinally, and then blindly observed under a stereomicroscope by three trained examiners. Microleakage was evaluated using a 0-4 scale for dye penetration, and data were analyzed by Kruskal-Wallis test and Mann-Whitney U-test.

Results: The microleakage values were more in the group repaired with glass ionomer restorative material and the Chi-squared test showed no significant difference in between the groups repaired with bonded amalgam, composite resin, and ormocer, but showed significant difference between the groups repaired with ormocer and glass ionomer restorative materials and between composite resin and glass ionomer restorative materials.

Conclusion: None of the restorative techniques evaluated were able to completely eliminate marginal microleakage.

Clinical significance: The results seem to be favorable within the limits of the in vitro conditions of the present study; however, the in vivo conditions are the best for clinically relevant findings.

Keywords: Amalgam, Microleakage, Restoration.

The Journal of Contemporary Dental Practice (2020): 10.5005/jp-journals-10024-2872
\end{abstract}

\section{INTRODUCTION}

On a worldwide scale, dental amalgam is the most common direct filling restorative material used, especially for posterior teeth. Despite all the controversies regarding the adverse effects of mercury on health, amalgam has retained its position as one of the most commonly used restorative material. ${ }^{1}$

The popularity of amalgam might be attributed to its good mechanical properties, low cost, ease of application, high longevity, which has sustained its use despite numerous challenges and the development of alternatives. Amalgam has low technique sensitivity, good wear resistance, and self-sealing ability. ${ }^{2,3}$

Failure of dental restorations is the major concern in the dental practice. Survival and failure rates may be used as the measures of clinical performance. One of the major steps in the breakdown of the margin is extrusion of the amalgam along the margins and formation or enlargement of the tooth-amalgam gap. Creep rate has been found to correlate with the marginal breakdown of amalgam restorations; that is, the higher the creep magnitude, the greater the degree of marginal deterioration. ${ }^{4}$

The use of amalgam bonding agents has become popular in the restoration of posterior teeth, demonstrates many potential advantages, including tooth reinforcement, and increases the retention without the need of conventional cavity designs providing a conservative preparation, decreased postoperative sensitivity, better marginal adaptation, decreased microleakage, and reduction of secondary caries. ${ }^{4}$ $\overline{1,4,5 \text { Department of Conservative Dentistry and Endodontics, KLE }}$ Vishwanath Katti Institute of Dental Sciences, Belagavi, Karnataka, India

${ }^{2}$ Department of Conservative Dentistry and Endodontics, Dr HSRSM Dental College, Hingoli, Maharashtra, India

${ }^{3}$ Department of Conservative Dentistry and Endodontics, PM Nadagowda Memorial Dental College and Hospital, Bagalkot, Karnataka, India

${ }^{6}$ Department of Conservative Dentistry and Endodontics, Subbaiah Institute of Dental Sciences, Shivamogga, Karnataka, India

Corresponding Author: Aniket Chavan, Department of Conservative Dentistry and Endodontics, KLE Vishwanath Katti Institute of Dental Sciences, Belagavi, Karnataka, India, Phone: +91 9739817560, e-mail: agc290987@gmail.com

How to cite this article: Chavan A, Darak P, Vallabhaneni S, et al. Comparative Evaluation of Efficacy of Four Different Materials in the Repair of Amalgam Restorations: An In Vitro Study. J Contemp Dent Pract 2020;21(7):741-747.

Source of support: Nil

Conflict of interest: None

Resin-based tooth-colored materials have become increasingly popular as overall restorative materials, including posterior restoration applications. ${ }^{5,6}$ Resin composites have also been shown to successfully repair amalgam restorations, because of the improved filler content, improved use of adhesive agent, fracture

(c) The Author(s). 2020 Open Access This article is distributed under the terms of the Creative Commons Attribution 4.0 International License (https://creativecommons. org/licenses/by-nc/4.0/), which permits unrestricted use, distribution, and non-commercial reproduction in any medium, provided you give appropriate credit to the original author(s) and the source, provide a link to the Creative Commons license, and indicate if changes were made. The Creative Commons Public Domain Dedication waiver (http://creativecommons.org/publicdomain/zero/1.0/) applies to the data made available in this article, unless otherwise stated. 
resistance, better marginal adaptation, and minimal shrinkage. ${ }^{7}$ Ormocers are organically modified ceramics which is a combination of a polycondensed inorganic and organic networks. Ormocers have an inorganic backbone based on the $\mathrm{SiO}_{2}$ and are functionalized with polymerizable organic units. This produces 3-dimensional polymeric composites. Ormocers are mechanically stable, chemically resistant, esthetic, and advantageous when compared to conventional composites like outstanding biocompatibility, minimal shrinkage; resistance to masticatory loading, and the bond strength achieved is stable. ${ }^{8}$

Glass ionomer cement $(\mathrm{GIC})$ is a unique restorative material with many uses in clinical practice. What differentiates GIC from other restoratives is their chemistry, which allows them to be selfadhesive to enamel and dentin and provide for caries-protective fluoride release at the margins of restorations, as well as their ability to have the fluoride within their chemical matrix recharged by outside exposure to the other fluoride-containing materials. Other unique features include their moisture tolerance, allowing GIC to be used for a wide variety of clinical applications. The successful addition of new restorative materials to an existing restoration may be the most conservative course of treatment in certain situations. Occasionally, the repair of an amalgam restoration can provide a less invasive procedure than its complete removal and replacement. The success of such procedures may be directly affected by the strength of the bond and microleakage between the old and new restorative materials and between tooth structure and restorative materials. ${ }^{9,10}$

Microleakage tests are the useful methods to evaluate the sealing performance of adhesive systems. Among the different methods employed, dye penetration measurement performed on the sections of restored teeth is the most commonly used technique due to its low cost and simplicity. ${ }^{10}$ This in vitro study was aimed to assess the repair quality of amalgam restorations using bonded amalgam, composite resin, ormocer and glass ionomer restorative material at restoration/repair and repair/ tooth interfaces after partial removal of preexisting amalgam by quantitative microleakage assessment using silver nitrate dye and stereomicroscopic analysis.

\section{Materials and Methods}

The present study was conducted in the Department of Conservative Dentistry and Endodontics at PMNM Dental College and Hospital in Bagalkot. Sixty freshly extracted premolars were included in the present study. Cleaning of the roots was done for removing the debris. Before utilizing, all the specimens were disinfected by thymol solution (0.5\%). Random division of all the specimens was done into four different groups with 15 samples in each group as shown in Table 1: Group I= bonded amalgam (3M ESPE, Adper), Group II = composite resin (Filtek, Tetric EvoCeram), Group III = ormocer (Ceram X, Dentsply) and Group IV = packable glass ionomer restorative material (Fuji IX).

\section{Specimen Procedure}

Preparation of class 1 cavities was done on the occlusal surface to be $2 \mathrm{~mm}$ wide, $4 \mathrm{~mm}$ deep, and $3 \mathrm{~mm}$ long with the help of a high-speed handpiece and a carbide plain fissure bur \# 245. Replacement of the burs was done after making every five cavities. The measurement of the dimension was done using periodontal probe for the maintenance of uniformity.
Table 1: Description of materials used in the present study

\begin{tabular}{|c|c|c|}
\hline Materials & Description & Manufacturer \\
\hline $\begin{array}{l}\text { Composite resin } \\
\text { FiltekZ350 }^{T M}\end{array}$ & $\begin{array}{l}\text { Filtek TM Z350 universal } \\
\text { restorative material is a visible } \\
\text { light-activated, radiopaque } \\
\text { restorative composite resin } \\
\text { designed for using in anterior } \\
\text { and posterior restorations. } \\
\text { The fillers are a combination } \\
\text { of aggregated zirconia/silica } \\
\text { cluster filler with an average } \\
\text { cluster particle size of } \\
0.6-1.4 \text { microns with a primary } \\
\text { particle size of } 5-20 \text { nm and } \\
\text { non-agglomerated/non- } \\
\text { aggregated } 20-n m \text { silica filler. } \\
\text { The inorganic filler loading } \\
\text { is about } 78.5 \% \text { by wt (59.5\% } \\
\text { by volume). Filtek TM Z350 } \\
\text { universal restorative material } \\
\text { contains bis-GMA, UDMA, and } \\
\text { TEGDMA resins }\end{array}$ & $\begin{array}{l}\text { 3M ESPE, } \\
\text { India }\end{array}$ \\
\hline $\begin{array}{l}\text { Bonded amalgam } \\
\text { (3M ESPE, Adper) }\end{array}$ & $\begin{array}{l}\text { Contents: activator, primer, } \\
\text { adhesive, catalyst, and etchant }\end{array}$ & Adper \\
\hline Ormocer (Ceram X) & $\begin{array}{l}\text { Designed for using in anterior } \\
\text { and posterior restorations Bis- } \\
\text { GMA resins }\end{array}$ & Dentsply \\
\hline $\begin{array}{l}\text { Packable glass } \\
\text { ionomer restorative } \\
\text { material (Fuji IX) }\end{array}$ & $\begin{array}{l}\text { Fluoride releasing and } \\
\text { posterior restorations }\end{array}$ & Dentsply \\
\hline
\end{tabular}

\section{Restorative Procedure}

Restoration of the teeth specimens was done using handcondensed amalgam, into the preparations with the purpose of covering entire walls along with cavosurface margins. This was followed by carving of the tooth contour using sharp carver. After the time period of 72 hours, polishing of the restorations were done followed by storage in saline solution at $37^{\circ} \mathrm{C}$.

\section{Repair Procedure}

In the amalgam restorations, preparation of fresh class 1 cavities ( $1 \mathrm{~mm}$ wide, $2 \mathrm{~mm}$ deep, and $3 \mathrm{~mm}$ long) was done along the cavosurface margins with the aim of simulating a defect. After the sample preparation, the teeth samples were randomly divided into four different groups with fifteen specimens in each group: Group I = bonded amalgam (3M ESPE, Adper), Group II = composite resin (FILTEK, Tetric EvoCeram), Group III = ormocer (Ceram X, Dentsply), and Group IV = packable glass ionomer restorative material (Fuji IX). All the samples were restored using the materials as per their respective groups.

\section{Thermal Cycling and Microleakage Testing}

Thermocycling of all the specimens was done (500 cycles) between $5^{\circ} \mathrm{C}$ and $55^{\circ} \mathrm{C}$ with a one-minute dwell time. Glass ionomer was used for filling up the teeth apice (Ketac Bond-3M ESPE, St Paul, MN, USA) followed by coating with nail varnish (2 layers) leaving the repair margins uncoated. In the absence of light, immersing of the specimens was done in $50 \%$ silver nitrate solution for 24 hours at $37^{\circ} \mathrm{C}$. Then, they were washed in running water and immersed 
into another vial with photodeveloping solution (Decktol, Kodak, Sao Jose Dos Campos, SP, Brazil) for 6 hours under continuous illumination to reduce the formation of precipitated silver ions. Each specimen was longitudinally sectioned by a cutting machine (Dentorium, New York) in a buccolingual direction through the restoration center. The sections were examined blindly by three trained examiners with a stereomicroscope (Lawrence \& Mayo) at $50 \times$ magnification. The data collected were statistically analyzed.

Each section was then graded for microleakage at the repair/ tooth and repair/restoration interfaces as follows (Fig. 1):

- Score 0-no dye infiltration (Fig. 1A)

- Score 1-dye penetration up to one-third of the repair axial wall (Fig. 1B)

- Score 2-dye penetration up to two-thirds of the repair axial wall (Fig. 1C)

- Score 3-dye penetration onto the entire repair axial wall (Fig. 1D)

- Score 4-dye penetration onto the pulpal wall of the repair (Fig. 1E).

\section{Results}

This in vitro study was done to compare the microleakage of amalgam restorations which was repaired with bonded amalgam, composite resin, ormocer, and glass ionomer restorative material. The study included a sample size of 60 teeth and randomly divided into four groups containing 15 teeth each (Fig. 2). The results showed that there was an overall statistical significant difference between the four groups (Table 2 and Fig. 3). No statistical significant difference was observed between the bonded amalgam, composite resin, and ormocer groups. However, there was a statistical significant difference between the composite resin and GIC and the ormocer and GIC groups.

For the repair/restoration interface, the microleakage values were more in the group repaired with glass ionomer restorative material (Table 3 and Fig. 4). And, the Chi-squared test showed no significant difference in between the groups repaired with bonded amalgam, composite resin, and ormocer, but showed significant difference between the groups repaired with ormocer and glass ionomer restorative material and between composite resin and glass ionomer restorative material (Fig. 5).

For the repair/tooth interface, the microleakage values were more in the group repaired with glass ionomer restorative material. And the Chi-squared test showed no significant difference in between the groups repaired with bonded amalgam, composite resin, and ormocer, but showed significant difference between the groups repaired with ormocer and glass ionomer restorative material and between composite resin and glass ionomer restorative material (Tables 4 and 5).

The mean microleakage values of the group repaired with glass ionomer restorative material showed highest readings (3.1) indicating more microleakage in this group followed by the group repaired with bonded amalgam (1.9) and composite resin (0.7). Mean microleakage values of the group repaired with ormocer (0.6) were least, including less microleakage. The mean microleakage values of the group repaired with glass ionomer restorative material showed highest readings (2.5) indicating more microleakage in this group followed by the group repaired with bonded amalgam (1.7) and composite resin (0.9). Mean microleakage values of the group repaired with ormocer (0.6) were least, including less microleakage (Tables 6 and 7).

The readings showed that the group repaired with glass ionomer restorative material was the most to leak followed by the groups repaired with bonded amalgam, composite resin, and ormocer, where the ormocer group showed least microleakage.

\section{Discussion}

Amalgam restoration repair is regarded as efficacious and reasonable alternative treatment in terms of cost-effectiveness in comparison with whole replacement. ${ }^{10}$ In this study, human premolar teeth were selected because these teeth are extracted more frequently for orthodontic purpose and are easily available. The present study showed that all the four restorative materials bonded amalgam, composite resin, ormocer, and GIC that were investigated exhibited microleakage at the repair/restoration and the repair/tooth interfaces. Among these materials, repair with ormocer showed less microleakage than that of composite resin followed by bonded amalgam and GIC at both repair/tooth and repair/restoration interfaces, but a statistical significant difference was found between ormocer/GIC groups and composite resin/ GIC groups.

The present study showed that there was no statistically significant difference between the ormocer and the composite resin groups. Our results are in agreement with the study by Sharma et al. ${ }^{11}$ where there was no statistically significant difference between the ormocer and composite resin groups. The ormocer and composite resin exhibited the best sealing ability. The lowest polymerization shrinkage microfilled composite resins mainly contain filler particles with a mean diameter of less than $100 \mathrm{~nm}$ and such fillers are called nanofillers. The composite resin showed lesser microleakage when compared to bonded amalgam in this study which is in agreement with a study of Popoff et al. ${ }^{4}$ For the repair/restoration interface,
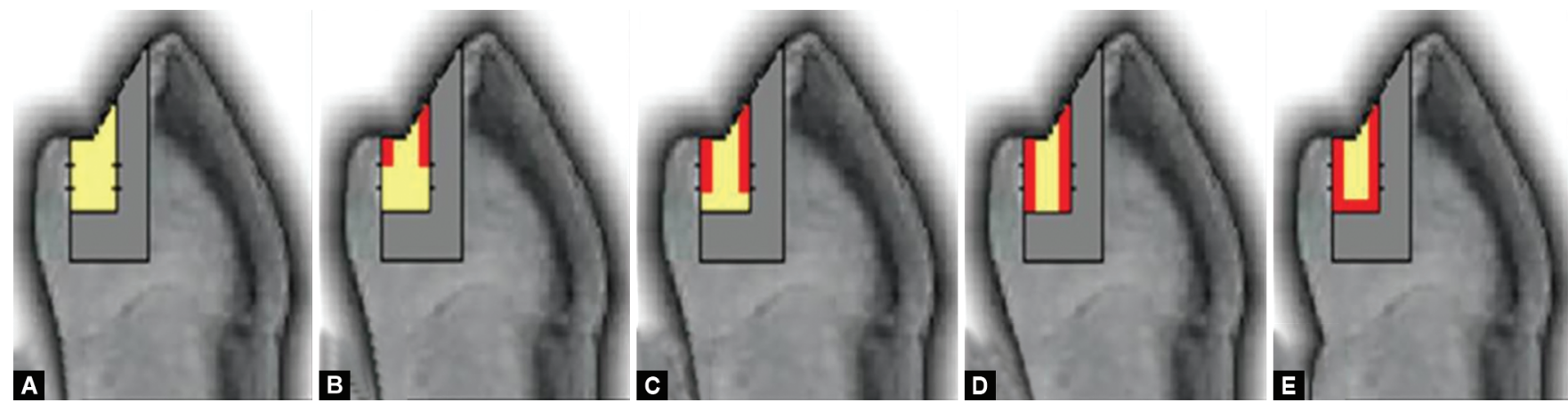

Figs 1 A to E: (A) Score 0; (B) Score 1; (C) Score 3; (D) Score 3; (E) Score 4 

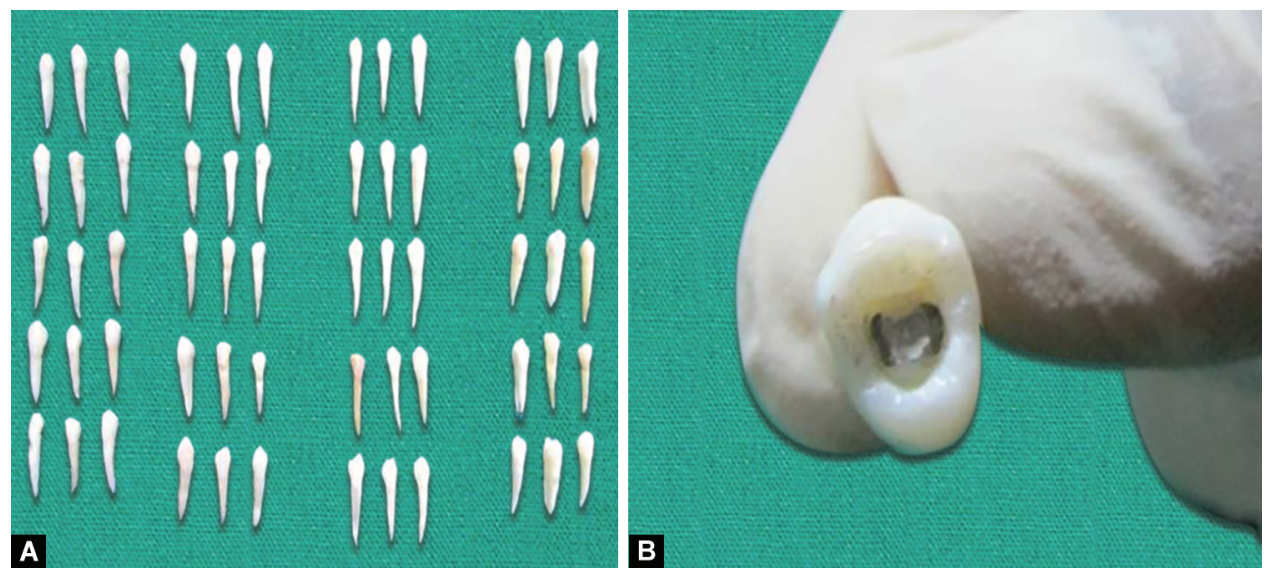

Figs 2A and B: (A) Specimens; (B) Defect in the restoration created

Table 2: Status of microleakage for the repair/restoration interface in four different groups

\begin{tabular}{|c|c|c|c|c|c|c|c|c|c|}
\hline Microleakage & $\begin{array}{l}\text { Bonded } \\
\text { amalgam }\end{array}$ & (\%) & $\begin{array}{l}\text { Composite } \\
\text { resin }\end{array}$ & (\%) & Ormocer & (\%) & $\begin{array}{l}\text { Glass ionomer } \\
\text { cement }\end{array}$ & (\%) & Total \\
\hline Score 0 & 6 & 40.00 & 9 & 60.00 & 12 & 80.00 & 1 & 6.67 & 28 \\
\hline Score 1 & 1 & 6.67 & 4 & 26.67 & 1 & 6.67 & 1 & 6.67 & 7 \\
\hline Score 2 & 1 & 6.67 & 0 & 0.00 & 0 & 0.00 & 2 & 13.33 & 3 \\
\hline Score 3 & 3 & 20.00 & 1 & 6.67 & 0 & 0.00 & 3 & 20.00 & 7 \\
\hline Score 4 & 4 & 26.67 & 1 & 6.67 & 2 & 13.33 & 8 & 53.33 & 15 \\
\hline Total & 15 & 100.00 & 15 & 100.00 & 15 & 100.00 & 15 & 100.00 & 60 \\
\hline
\end{tabular}

Overall Chi-squared $=28.4762, p=0.00472^{*}$

Bonded amalgam vs composite resin, Chi-squared $=6.2001, p=0.1852$

Bonded amalgam vs ormocer, Chi-squared $=6.6673, p=0.1551$

Bonded amalgam vs GIC, Chi-squared $=5.2383, p=0.2645$

Composite resin vs ormocer, Chi-squared $=3.5622, p=0.3131$

Composite resin vs GIC, Chi-squared $=16.6445, p=0.0021^{*}$

Ormocer vs GIC, Chi-squared $=17.9082, p=0.0012^{*}$

${ }^{*} p<0.05$

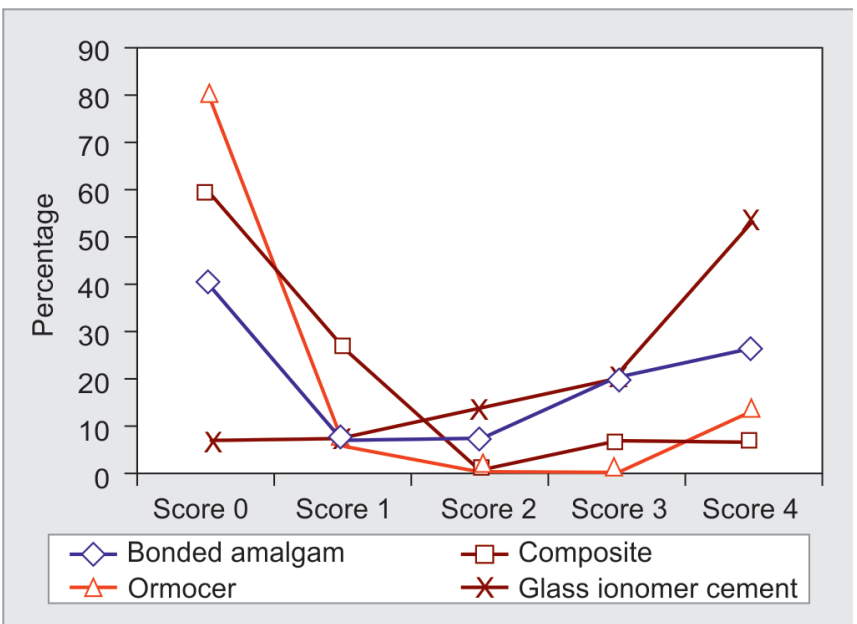

Fig. 3: Frequencies of dye penetration scores of marginal microleakage for repair/restoration interfaces in four groups

bonded amalgam showed a higher level of microleakage than repair with composite resin. ${ }^{12,13}$

Although several studies have shown that primers and adhesives form ionic bonds with metal oxides or with the active metal compounds of the amalgam, the existence of a true chemical bond between composite resin and amalgam is controversial. ${ }^{4}$ However, the marginal leakage around composite resin restorations is reduced to a minimum at repair/tooth interface. The reason for less microleakage at repair/tooth interface may be due to the reason that composite resin was introduced within the microporosities of the etched enamel, photocuring of composite resin through the thin enamel may reduce its polymerization shrinkage which may lead to decreased marginal gap and less amount of microleakage and the introduction of improved dentin bonding agents made it possible to develop a continuous bonding of the resin material from dentinal wall to enamel wall. ${ }^{14-16}$

The marginal leakage is more at the repair/restoration interface. It is interesting to note that the results of the current study highlighted the repair/restoration interface as the weakest part of the repaired restorative complex. This can be clarified in a way that a better adhesion of the bonding agent to existing amalgam is achieved if the roughened surface is not acid-etched. The results of the present study are consistent with the results obtained in the study conducted by Maroney et al. and also with Cardash et al. who described microleakage at the etched amalgam/composite resin interface. Etching of the amalgam surface in the present study showed an adverse effect on the leakage between amalgam and composite resin. ${ }^{17,18}$ 
Table 3: Status of microleakage for the repair/tooth interface in four different groups

\begin{tabular}{|c|c|c|c|c|c|c|c|c|c|}
\hline Microleakage & $\begin{array}{l}\text { Bonded } \\
\text { amalgam }\end{array}$ & (\%) & $\begin{array}{l}\text { Composite } \\
\text { resin }\end{array}$ & (\%) & Ormocer & (\%) & $\begin{array}{l}\text { Glass ionomer } \\
\text { cement }\end{array}$ & (\%) & Total \\
\hline Score 0 & 3 & 20.00 & 8 & 53.33 & 10 & 66.67 & 2 & 13.33 & 23 \\
\hline Score 1 & 3 & 20.00 & 3 & 20.00 & 2 & 13.33 & 1 & 6.67 & 9 \\
\hline Score 2 & 4 & 26.67 & 2 & 13.33 & 2 & 13.33 & 4 & 26.67 & 12 \\
\hline Score 3 & 5 & 33.33 & 2 & 13.33 & 1 & 6.67 & 4 & 26.67 & 12 \\
\hline Score 4 & 0 & 0.00 & 0 & 0.00 & 0 & 0.00 & 4 & 26.67 & 4 \\
\hline Total & 15 & 100.00 & 15 & 100.00 & 15 & 100.00 & 15 & 100.00 & 60 \\
\hline
\end{tabular}

Overall Chi-squared $=25.6722, p=0.01197^{*}$

Bonded amalgam vs composite resin, Chi-squared $=4.2252, p=0.2318$

Bonded amalgam vs ormocer, Chi-squared $=7.3032, p=0.0631$

Bonded amalgam vs GIC, Chi-squared $=5.3113, p=0.2527$

Composite resin vs ormocer, Chi-square $=0.7562, p=0.8602$

Composite resin vs GIC, Chi-squared $=9.9323 p=0.0423^{*}$

Ormocer vs GIC, Chi-squared $=12.1332 p=0.0116^{*}$

${ }^{*} p<0.05$

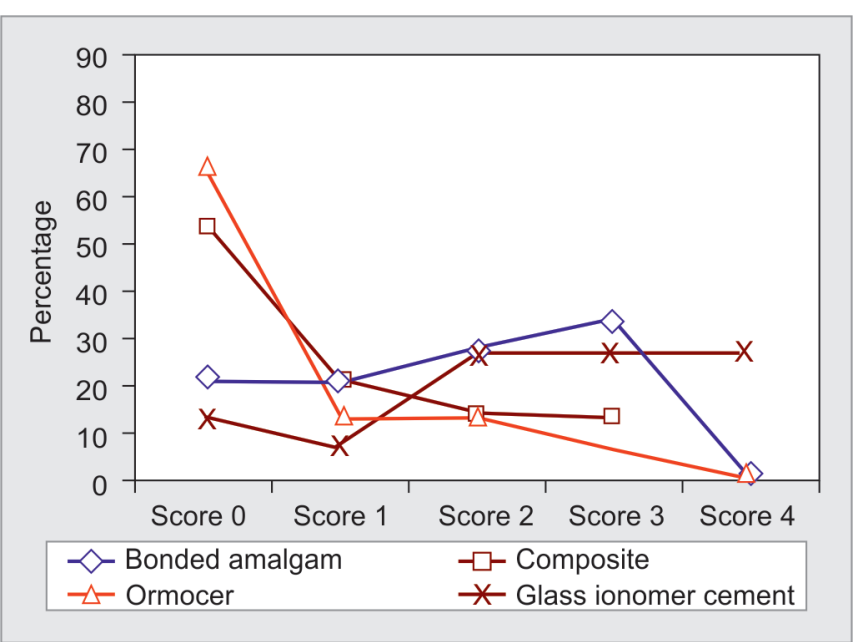

Fig. 4: Frequencies of dye penetration scores of marginal microleakage for repair/tooth interfaces in four groups

One of the explanations for the increased amount of leakage at the composite resin/amalgam interface was that it might not be possible to completely remove the gel from the roughened amalgam surface before applying bonding agent and composite resin. The findings in the present study are concomitant with the study conducted by Hadavi et al. Some reaction between metal and bonding agent might be responsible for better adhesion, and acid etch disrupts this process. ${ }^{19}$

The present study showed that bonded amalgam has less microleakage when compared to GIC which is in agreement with the study conducted by Hoshi et al. ${ }^{20}$ Our results agree with the data reported with this in vitro study since no material was able to eliminate microleakage completely and the best results were obtained with the application of adhesive materials and superior performance that resulted in lesser microleakage when compared to GIC.

The maximum microleakage was seen with the GIC group in the present study which is in agreement with Alperstein et al. where showed slight to moderate marginal leakage with GIC in contrast to none or minimal leakage with amalgam and composite resin was seen. The maximum microleakage produced may be due to
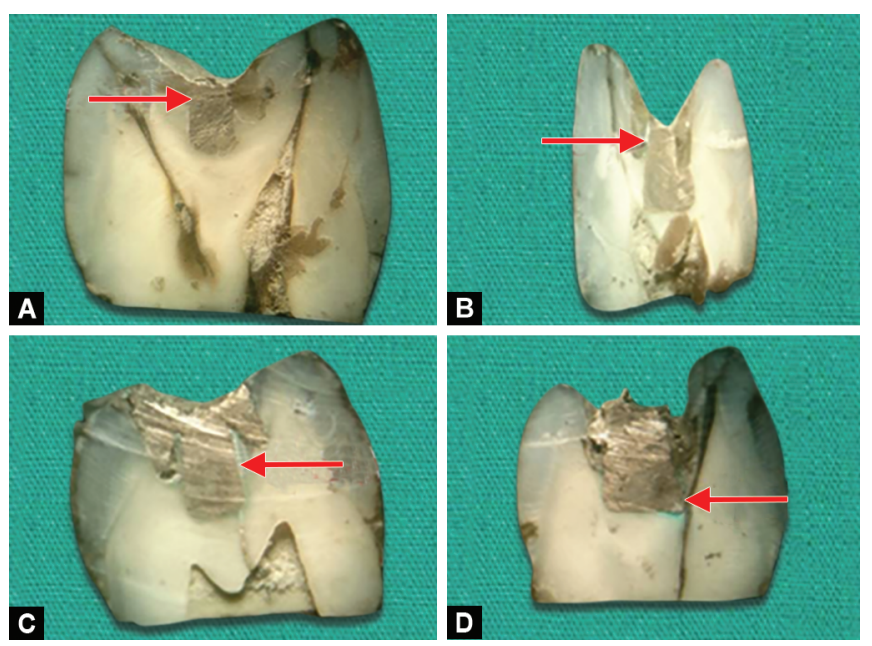

Figs $5 A$ to $D$ : (A) No dye penetration; (B) Dye penetration along onethird of repaired axial wall; (C) Dye penetration along two-thirds of the repaired axial wall; (D) Dye penetration onto the pulpal wall of repair

the fact that no primer was used with this type of glass ionomer. The function of primer is to modify the smear layer and adequately wet the tooth surface to facilitate adhesion of the material to the hard tissue. ${ }^{6,21}$

The present study showed statistical significant difference between the ormocer and GIC group which is in accordance with a study conducted by Gupta et al. which showed statistically significant difference between ormocer and GIC where ormocer showed high shear bond strength than GIC indicating less microleakage than GIC. ${ }^{6}$ Also, a statistically significant difference was observed between the composite resin and GIC group, where composite resin showed less microleakage than GIC which is in concurrence with a study by Ersin NK et al. where there was a statistical significant difference between the two groups. ${ }^{22}$

In the present study, none of the four restorative materials prevented the dye penetration. This result is in agreement with the study conducted by Gerdolle et al. ${ }^{23}$ The results concluded that none of the four restorative materials prevented the dye penetration. The ormocer and packable composites exhibited the lowest microleakage, followed by resin-modified glass ionomer. 
Efficacy of Different Materials in Repair of Amalgam Restorations

Table 4: Comparison of four groups with respect to microleakage for repair/restoration interfaces by Kruskal-Wallis ANOVA

\begin{tabular}{llllll}
\hline Groups & Mean & SD & Median & Sum of ranks & Hvalue \\
\hline Bonded amalgam & 1.9 & 1.8 & 2.0 & 494.0 & 19.5517 \\
Composite resin & 0.7 & 1.2 & 0.0 & 353.5 & $0.0002^{*}$ \\
Ormocer & 0.6 & 1.4 & 0.0 & 312.0 & \\
Glass ionomer cement & 3.1 & 1.3 & 4.0 & 670.5 & \\
\hline
\end{tabular}

${ }^{*} p<0.05$

Table 5: Pairwise comparison of four groups with respect to microleakage for repair/restoration interfaces by Mann-Whitney U-test

\begin{tabular}{|c|c|c|c|c|c|c|c|}
\hline Groups & Mean & $S D$ & Median & Sum of ranks & Uvalue & Zvalue & $p$ value \\
\hline Bonded amalgam & 1.9 & 1.8 & 2.0 & 269.50 & & & \\
\hline Composite resin & 0.7 & 1.2 & 0.0 & 195.50 & 75.50 & -1.5347 & 0.1249 \\
\hline Bonded amalgam & 1.9 & 1.8 & 2.0 & 276.50 & & & \\
\hline Ormocer & 0.6 & 1.4 & 0.0 & 188.50 & 68.50 & -1.8250 & 0.0680 \\
\hline Bonded amalgam & 1.9 & 1.8 & 2.0 & 188.00 & & & \\
\hline Glass ionomer cement & 3.1 & 1.3 & 4.0 & 277.00 & 68.00 & -1.8458 & 0.0649 \\
\hline Composite resin & 0.7 & 1.2 & 0.0 & 251.00 & & & \\
\hline Ormocer & 0.6 & 1.4 & 0.0 & 214.00 & 94.00 & -0.7673 & 0.4429 \\
\hline Composite resin & 0.7 & 1.2 & 0.0 & 147.00 & & & \\
\hline Glass ionomer cement & 3.1 & 1.3 & 4.0 & 318.00 & 27.00 & -3.5464 & $0.0004^{*}$ \\
\hline Ormocer & 0.6 & 1.4 & 0.0 & 149.50 & & & \\
\hline Glass ionomer cement & 3.1 & 1.3 & 4.0 & 315.50 & 29.50 & -3.4427 & $0.0006^{*}$ \\
\hline
\end{tabular}

${ }^{*} p<0.05$

Table 6: Comparison of four groups with respect to microleakage for repair/tooth interfaces by Kruskal-Wallis ANOVA

\begin{tabular}{lllllll}
\hline Groups & Mean & SD & Median & Sum of ranks & H value & p value \\
\hline Bonded amalgam & 1.7 & 1.2 & 2.0 & 526.5 & 3.1261 & \\
Composite resin & 0.9 & 1.1 & 0.0 & 358.0 & $30007^{*}$ \\
Ormocer & 0.6 & 1.0 & 0.0 & 642.0 & \\
Glass ionomer cement & 2.5 & 1.4 & 3.0 & & \\
\hline
\end{tabular}

${ }^{*} p<0.05$

Table 7: Pairwise comparison of four groups with respect to microleakage for repair/tooth interfaces by Mann-Whitney U-test

\begin{tabular}{|c|c|c|c|c|c|c|c|}
\hline Groups & Mean & $S D$ & Median & Sum of ranks & Uvalue & Zvalue & pvalue \\
\hline Bonded amalgam & 1.7 & 1.2 & 2.0 & 278.50 & & & \\
\hline Composite resin & 0.9 & 1.1 & 0.0 & 186.50 & 66.50 & -1.9080 & 0.0564 \\
\hline Bonded amalgam & 1.7 & 1.2 & 2.0 & 292.50 & & & \\
\hline Ormocer & 0.6 & 1.0 & 0.0 & 172.50 & 52.50 & -2.4887 & $0.0128^{*}$ \\
\hline Bonded amalgam & 1.7 & 1.2 & 2.0 & 195.50 & & & \\
\hline Glass ionomer cement & 2.5 & 1.4 & 3.0 & 269.50 & 75.50 & -1.5347 & 0.1249 \\
\hline Composite resin & 0.9 & 1.1 & 0.0 & 248.00 & & & \\
\hline Ormocer & 0.6 & 1.0 & 0.0 & 217.00 & 97.00 & -0.6429 & 0.5203 \\
\hline Composite resin & 0.9 & 1.1 & 0.0 & 163.50 & & & \\
\hline Glass ionomer cement & 2.5 & 1.4 & 3.0 & 301.50 & 43.50 & -2.8620 & $0.0042^{*}$ \\
\hline Ormocer & 0.6 & 1.0 & 0.0 & 154.00 & & & \\
\hline Glass ionomer cement & 2.5 & 1.4 & 3.0 & 311.00 & 34.00 & -3.2560 & $0.0011 *$ \\
\hline
\end{tabular}

${ }^{*} p<0.05$

The highest microleakage values were seen with compomer group. Regarding the polymerization shrinkage, composite resin demonstrated the lowest values, followed by ormocer and compomer. The resin-modified GIC presented the highest values. However, this study could not demonstrate that higher polymerization shrinkage resulted in lower sealing ability, and thus, polymerization shrinkage was confirmed not to be the only factor inducing interfacial microleakage. 


\section{Conclusion}

None of the restorative techniques evaluated were able to completely eliminate marginal microleakage. For the repair/tooth interface, repair with ormocer demonstrated a greater sealing ability than repair with bonded amalgam, composite resin, and glass ionomer restorative material. For the repair/restoration interface, glass ionomer restorative material showed a higher level of microleakage than repair with composite resin, bonded amalgam, and ormocer.

\section{References}

1. Eliades $G$, Eliades T, Brantley WA, et al. Dental materials in vivo aging and related phenomena. 2003.61-77.

2. Moncada G, Fernández E, MartínC, et al. Increasing the longevity of restorations by minimal intervention: a two-year clinical trial. Oper Dent 2008;33(3):258-264. DOI: 10.2341/07-113.

3. Baratieri LN, Monteiro JS, Andrada MA. Amalgam repair: a case report. Quintessence Int 1992;23(8):527-531.

4. Popoff DAV, Gonçalves FS, Magalhães CS, et al. Repair of amalgam restorations with composite resin and bonded amalgam: A microleakage study. J Dent Res 2011;22(6):799-803. DOI: 10.4103/0970-9290.94672.

5. Jain. P. Ormocer: bio-compatible replacement for amalgam, composites and compomers. J Conserv Dent 2001;4:79-83.

6. Gupta SK, Gupta J, Saraswathi V, et al. Comparative evaluation of microleakage in class $V$ cavities using various glass ionomer cements: an in vitro study. J Interdiscip Dent 2012;2(3):164-169. DOI: 10.4103/2229-5194.113245.

7. Gourley JM, Ambrose ER. Veneering amalgam restorations. J Can Dent Assoc 1983;48:49-50.

8. Shivanna V, Aswini TS. Evaluation of microleakage in class I amalgam composite compound restoration at the three different interfaces - an in vitro study. J Conserv Dent 2003;6:107-110.

9. Hadavi F, Hey JH, Ambrose ER, et al. Effect of different adhesive systems on microleakage at the amalgam/composite resin interface. Oper Dent 1993;18(1):2-7.

10. Mahler DB, Bryant RW. Microleakage of amalgam alloys: an update. J Am Dent Assoc 1996;127(9):1351-1356. DOI: 10.14219/jada. archive.1996.0446.

11. Sharma S, Padda BK, Choudhary V. Comparative evaluation of residual monomer content and polymerization shrinkage of a packable composite and an ormocer. J Conserv Dent 2012;15(2):161-165. DOI 10.4103/0972-0707.94592.

12. Silva AF, Piva E, Demarco FF, et al. Microleakage in conventional and bonded amalgam restorations: influence of cavity volume. Oper Dent 2006;31(3):377-383. DOI: 10.2341/05-49.

13. Davis R, Overton JD. Efficacy of bonded and nonbonded amalgam in the treatment of teeth with incomplete fractures. J Am Dent Assoc 2000;131(4):469-478. DOI: 10.14219/jada.archive.2000.0203.

14. Holan G, Chosack A, Eidelman E. Clinical evaluation of class II combined amalgam-composite restorations in primary molars after 6 to 30 months. J Dent Child 1996;63(5):341-345.

15. Franchi $M$, Breschi $L$, Ruggeri O. Cusp fracture resistance in composite - amalgam combined restorations. J Dent 1999;27(1):47-52. DOI: 10.1016/s0300-5712(98)00020-7.

16. Royse MC, Ott MW, Mathieu GP. Dentin adhesive superior to copal varnish in preventing microleakage in primary teeth. Pediatr Dent 1996;18(7):440-443.

17. Maroney WF, Blank LW, Hargrave JW, et al. Microleakage at the etched amalgam/composite resin interface of etched-metal resin-bonded retainers. Gen Dent 1988;36(1):18-19.

18. Cardash HS, Bichacho N, Imber S, et al. A combined amalgam and composite resin restoration. J Prosthet Dent 1990;65(5):502-505. DOI: 10.1016/0022-3913(90)90065-k.

19. Hadavi F, Hey JH, Czech D, et al. Assessing microleakage at the junction between amalgam and composite resin to amalgam: a new in vitro method. Oper Dent 1991;16(1):6-12.

20. Hoshi AT, Bonifacio DA, Silva SM, et al. In vitro evaluation of the marginal microleakage of amalgam restorations associated with dentin adhesive, glass ionomer cement and cavity varnish by means of different evaluating methods. J Appl Oral Sci 2005;13(1):10-14. DOI: 10.1590/s1678-77572005000100003.

21. Alperstein KS, Graver HT, Herold RCB. Marginal leakage of glass ionomer cement restorations. J Prosthet Dent 1983;50(6):803-807. DOI: 10.1016/0022-3913(83)90095-1.

22. Ersin NK, Candan U, Aykut A, et al. A clinical evaluation of resinbased composite and glass ionomer cement restorations placed in primary teeth using the ART approach: results at 24 months. J Am Dent Assoc 2006;137(11):1529-1536. DOI: 10.14219/jada.archive.2006. 0087.

23. Gerdolle DA, Mortier MS, Droz MS. Microleakage and polymerization shrinkage of various polymer restorative materials. J Dent Child 2008;75(2):125-133. 